\title{
Economics
}

2018; 7(1): 17-22

$\mathrm{http}: / /$ www.sciencepublishinggroup.com/j/eco

doi: 10.11648/j.eco.20180701.13

ISSN: 2376-659X (Print); ISSN: 2376-6603 (Online)

\section{An Econometric Assessment of the Impact of Inflation on Economic Growth: A Case Study of Zimbabwe Economy}

\author{
Shame Mukoka \\ Faculty of Commerce, Zimbabwe Open University, Harare, Zimbabwe \\ Email address: \\ smukoka49@gmail.com

\section{To cite this article:} \\ Shame Mukoka. An Econometric Assessment of the Impact of Inflation on Economic Growth: A Case Study of Zimbabwe \\ Economy.Economics.Vol. 7, No. 1, 2018, pp. 17-22. doi: 10.11648/j.eco.20180701.13
}

Received: April 6, 2018; Accepted: April 20, 2018; Published: May 16, 2018

\begin{abstract}
This study sought to determine the impact of inflation on Economic growth in Zimbabwe. The time series yearly data for Inflation and Economic Growth (GDP) from 1990 to 2017 were used for the study. Ordinary Least Squares (OLS) was used to determine the impact of inflation on Economic growth. Some Stationarity and Cointegration tests were carried out. Data became stationarity after first and second differencing using Augmented Dickey Fuller Test. There was also evidence of cointegration between the two variables using the Johansen Cointegration Test. The results of the study established no relationship between Inflation and Gross Domestic Product in Zimbabwe. These results have important policy implications, implying that controlling inflation is a necessary but not a pre-condition for promoting economic growth in Zimbabwe. Thus, the Zimbabwean government should focus on maintaining inflation at a low rate (single digit). In this regard the study concluded that all factors which cause an increase in the general price levels such as energy (petrol, diesel, gasoline, paraffin), exchange rates volatility, increase in money supply, poor agricultural production and so forth, should be kept on check, with the appropriate policies so as to foster economic growth.
\end{abstract}

Keywords: Inflation, Economic Growth, Terms of Trade, Cointegration and Stationarity

\section{Introduction}

Attaining sustainable economic growth, coupled with price stability continues to be the central objective of macroeconomic policies for most countries in the world today.In fact, for the achievement of the targets of economic and social development, the government of Zimbabwe has to face a lot of challenges. As the scenario is made complicated by unstable socio-political background internally, an increasingly globalize international economic environment, giving a meaning of greater amount of exposure to external shocks. Inflation, which is often perceived by many economists as enemy of society, due to its field of activity of increasing pricing of goods and services is one of the macro-economic indicators affecting the country. This paper examines empirically the relationship between inflation and economic growth (GDP) in Zimbabwe.

\section{Background of the Problem to the Study}

For many years, the subject that has preoccupied the government of Zimbabwe is the economic growth and inflation rate reduction. Inflation is defined as the increase in the level of prices and economic growth, usually referred to as the gross domestic product (GDP), measuring the market values of a country's final goods in a specified period, with economic growth being defined as the total output of goods and service of a country [1]. An increase in inflation means that prices would have beenrisen. Thus, with an increase in inflation, there tend to be a decline in the purchasing power of money, which reduces consumption. This, therefore, would result in the GDP decrease. In fact, high inflation makes investments less desirable, since it creates uncertainty for the future and also affect the balance of payments as exports become less competitive. As a result, GDP decreases further. It therefore, appears that GDP is negatively related to inflation. However, there are studies indicating that there 
may also be a positive relationship. The Phillips curve, for example, shows that high inflation is consistent with low rates of unemployment, implying that there is a positive impact on economic growth [2].

Zimbabwe is one of the African economy that has experienced hyperinflation, with the highest rate of $156.9 \%$ recorded in 2008 [3], against a Gross Domestic Product of 4.4 [3]. This disposition is reminiscent of the high inflation which the economy experienced from 2000 to 2008 and this constrained much of the industrial production capacity in the country. Most of the commodities in the market have been export products mainly from South Africa which would normally have higher prices than the prices in Zimbabwe. Also, the Zimbabwean dollar in the period 2006 to 2008 continued to be under severe pressure on both the official and parallel market exacerbating the inflation rate [4].

Zimbabwe recorded high levels of inflation, with $113.5 \%$ in 2004 , followed by $32.9 \%, 72 \%$, and $156.9 \%$ during the period 2006 to 2008 [3]. On the other hand, the country's GDP stood at $6.1 \%$ in 2004 followed by $5.6 \%, 5.4 \%$ and $4.4 \%$ during the period extending from 2006 to 2008 [3]. Policy makers came up with different market policies that sought to stabilise prices of goods and services. From 2009 to 2017, the country recorded an inflation average of $2.8 \%$ against an average GDP of $3.5 \%$, acceptable by all standards [5]. This study is a contribution to the growing literature aimed at understanding the impact of inflation on economic growth using Zimbabwe data with a more extended and updated period of study 1990 to 2017.

\section{Problem Statement}

Although the causes of inflation in Zimbabwe dates back from pre-colonial era, they were so severe during the period extending from 2004 to 2009 [3]. Some other macro-economic indicators such as unemployment, soared to unacceptable high levels. As if not enough, the introduction of multicurrency in 2009 , brought along with some challenges which companies failed to cope. This, henceforth, manifested in the general rise in the price of goods and services, thereby affecting the general welfare of economy's citizens. This study, therefore, seeks to determine empirically the impact of inflation on economic growth for the Zimbabwe economy.

\section{Research Objectives and Hypothesis}

The objective of this study is to determine the impact of inflation on economic growth for the Zimbabwe economy. It also seeks to make recommendations that would assist policy makers in managing inflation at the same time growing the economy. The hypothesis that pinned this study is that inflation is negatively related to economic growth.

\section{Review of Related Literature}

There is a huge survey of literature, which investigated theoretical and empirical aspects of relationship between inflation and economic growth. This section presents literature on the impact of inflation on economic growth.Fischer [6], showed that inflation and growth are negatively related. More specifically, he argues that growth, investments and productivity are negatively related to inflation and that capital accumulation and productivity growth are also negatively affected by budget deficits. Moreover, he states that some exceptional cases show that even though high growth is not necessarily associated with low inflation and small budget deficits, high rates of inflation are not consistent with permanent growth.

Barro [7] examined data for almost 100 countries for the period between 1960 and 1990 and found that the impact of inflation on growth and investment is significantly negative, given that a number of countries characteristics are constant. An average increase in inflation of ten per cent leads to a decrease of GDP and investment by 0.2 to 0.3 and 0.4 to 0.6 respectively. He also showed that even if inflation has a small impact on growth, this appears to be significant in the long run.

Bruno and Easterly [8] examined the relationship between inflation and economic growth and they found that this relationship exists only if there are high inflation rates. To determine the high rates of inflation, they set a threshold of 40 per cent. Above this threshold, inflation has a temporally negative impact on growth, whereas below this threshold, they found no robust relationship. The decrease in growth is temporary because after a high inflation crisis, the economy quickly recovers to its previous level. During this recovery, the economy can regain most, if not all of the loss of the economy's output.Their results are robust after controlling for other factors such as external shocks.

Ghosh and Phillips [9] studied the relationship between inflation and GDP for a large set of IMF countries for the period from 1960 to 1996 . They found that, generally, the coefficient, with respect to inflation, was negative. The findings were statistically significant. More specifically, they found two nonlinearities in the inflation-growth relationship. The relationship between these appeared to be negative for very low inflation rates (around two to three per cent). They also found a negative correlation for higher values but the relationship was convex, meaning that a decline in growth related to an increase of inflation from 10 to 20 percent larger than that related to an increase in inflation of from 40 to 50 percent.

Quartey [10] using the Johansen co-integration methodology, investigated whether the revenue maximising rate of inflation is growth maximising in Ghana. He found that there is a negative impact of inflation on economy growth. Furthermore, the study found a revenue maximising rate of inflation at 9.14 percent over the period 1970-2006 using the Laffer curve. He further established that the rate of inflation that is growth maximising is not a single digit one.

Hasanov [11] employed annual data set on growth rate of real GDP, Consumer Price Index Inflation and growth rate of real Gross Fixed Capital Formation to investigate whether there was any threshold effect of inflation on economic growth over the period of 2001-2009. Estimated threshold 
model indicated that there was non-linear relationship between inflation and economic growth in the Azerbaijani economy and threshold level of inflation for GDP growth was 13 percent. Inflation rate lower than 13 percent reflected statistically significant positive effect on GDP growth but this positive relationship became negative when inflation exceeded 13 percent. He added that, economic growth was expected to decline by about 3 percent when inflation increased above the 13 percent threshold.

Umaru and Zubairu, [12] suggested that all the variables in the unit root model were stationary and the results of causality revealed that GDP caused inflation and not inflation causing GDP. The results also revealed that inflation possessed a positive impact on economic growth through encouraging productivity and output level and on evolution of total factor productivity. Frimpong and Oteng-Abayie, [13] found a threshold effect of inflation on economic growth of 11 percent for Ghana over the period 1960-2008 though failing the test of significance at that level. They also estimated a robust 11 percent threshold inflation level with close coefficients after dropping growth rate of aggregate labour force and money supply growth which were found to be insignificant in the OLS models. They further revealed that even at relatively lower threshold levels, inflation is still significant. But their study however, failed to check for sensitivity of the estimated coefficients across sub-samples of the full sample period to establish a new evidence of the threshold effect. The study thus concluded by highlighting the need to extend the context of analysis to deal with lower threshold levels in search of that evidence.

On the other hand, Bick, Kremer, and Nautz [14] empirically expanded the scope of Khan and Senhadji, [15] by modelling a large panel-dataset of 124 industrialized and developing countries over the period from 1950 to 2004. Using a dynamic panel threshold model to shed light on the impact of inflation on economic growth, they found an inflation target of about 2 percent for industrialized countries and 17 percent for developing economies. Below the 17 percent threshold, the impact of inflation on economic growth remained insignificant, thus failing to support the growth-enhancing effects of inflation on economic growth in non-industrialized economies. Nell, [16] examined the issue if inflation was detrimental to economic growth or not by using Vector Auto Regressive (VAR) technique. Data for the period from 1960-1999 was used and his empirical results suggested that inflation within the single-digit zone may be beneficial to economic growth, while inflation in the double digit zone tends to limit economic growth.

Sergii, [17] found that growth-inflation interaction was strictly concave with some threshold level of inflation. Inflation threshold level is estimated using a non-linear least squares technique, and inference made by applying a bootstrap approach. The main findings were that inflation rate above 8 percent tend to slow down economic growth while below 8 percent promotes economic growth. Espinoza, Leon and Prasad, [18], examined threshold effect of inflation on economic growth by using a panel data of 165 countries including Oil Exporting Countries and Azerbaijan over the period of 1960-2007. Their study found that for all country groups' threshold level of inflation for economic growth was about 10 percent (with the exclusion of industrialized countries where threshold level was much lower). Estimated results suggested that inflation from higher than 13 percent decreases real non-oil GDP by 207 percent per year.

Lastly, review of literature on money supply and exchange rate influence on economic growth and inflation. Mehari and Wondafrash, [19] revealed that money supply had a direct impact on inflation. Mwase, [20] indicated that currency appreciation is associated with a decrease in inflation rate, with one quarter lag. The impact of inflation on economic growth is therefore, not a universal phenomenon which can be adopted in any country, thus it is still a moot point in countries where the two variables were not empirically tested. Therefore, this study undertakes this study in the Zimbabwe Context, so that the two macro-economic variables can be examined for informed policies.

\section{Materials and Method}

This section explores econometric methodology applied in the study to establish the impact of inflation on economic growth in Zimbabwe. The study employs secondary annual time series data set to examine the relationship between inflation and economic growth in Zimbabwe from 1990 to 2017. In this study, we use ordinary least squares (OLS) to estimate the equation. The estimation of the equation was such that unit root test is undertaken to determine the order of integration of the variables and that would be done using the Augmented Dickey Fuller (ADF) test. Given that all the variables are integrated of different orders, the second step is cointegration analysis which is applied for the estimation and determination of long-run equilibrium relationship among the variables and to check the integration of linear combination through the Johansen cointegration technique. Lastly, the OLS is considered after normality tests using the Jacque-Bera Test.

The theoretical basis of the model is a linear relationship between economic growth (GDP) as the dependent variable and the explanatory variables which include Inflation (INFLAT), unemployment (UNEMP), capital investment (CAPINVEST), government spending (GVSPE) and (TOT) terms of trade.

GDPCP $=\mathrm{F}($ INFLAT, UNEMP, CAPINVEST, GVSPE, TOT)

Where,

GDP-is gross domestic product

INFLAT-is inflation rate

UNEMP-is unemployment rate

CAPINVEST-is capital investment

TOT-is terms of trade

GVTSPE-is the government spending

Logarithms of the variables is then undertaken because most of the economic time series data are non-stationary. 


$$
\mathrm{GDPt}=\mathrm{a} 0+\mathrm{a} 1 \mathrm{INFLATt}+\mathrm{a} 2 \mathrm{UNEMPt}+\mathrm{a} \text { CAPINVESTt }+\mathrm{a} 4 \text { GVSPEt }+\mathrm{a} 5 \mathrm{TOT}+\mathrm{Ut}
$$

The expected signs from the regression equation to be estimated are as follows:

1. a1<0; a2 $<0 ;$ a3 $>0 ; a 4>0 ;$ a5 $>0$

\section{Data Analysis and Interpretation of Results}

This section focuses on the empirical estimation, presentation and economic interpretation of the regression results carried out using the methodology highlighted in the previous section.

Preliminary Tests

Table 1. Descriptive Statistics.

\begin{tabular}{lllllll}
\hline & CAPINVEST & GDP & GVTSPE & INFLAT & TOT & UNEMP \\
\hline Mean & 13.79864 & 1.208214 & 17.72250 & 3.200000 & 99.92536 & 5.457143 \\
Median & 14.44000 & 1.565000 & 17.92000 & -0.600000 & 98.15500 & 5.400000 \\
Maximum & 23.73000 & 15.45000 & 24.90000 & 157.0000 & 110.3100 & 6.900000 \\
Std. Dev & 6.551561 & 8.425782 & 6.139732 & 42.51694 & 5.496630 & 0.615497 \\
Skewness & -0.338555 & -0.382418 & -1.105332 & 2.145071 & 0.414851 & 0.270341 \\
Kurtosis & 2.046517 & 2.917295 & 3.789235 & 8.807419 & 2.734340 & 2.932562 \\
Jacque-Bera & 1.595544 & 0.690449 & 6.428245 & 60.82001 & 0.885478 & 0.346367 \\
Probability & 0.450331 & 0.708061 & 0.040191 & 0.000000 & 0.642275 & 0.840983 \\
Observations & 28 & 28 & 28 & 28 & 28 & 28 \\
\hline
\end{tabular}

Table 1, shows descriptive statistics of the dependant and explanatory variables used in the study for the period 1990 to 2017. Maximum and minimum statistics rule out the possibility of outliers in the data used. Classical linear regression requires that the residuals be normally distributed and judging by the probability values of the Jarque-Bera, four variables except for GVTSPE and INFLAT residuals do not follow a normal distributed therefore, the test for correlation among the variables can be conducted.

Correlation Test

Table 2. Correlation Matrix.

\begin{tabular}{llllll}
\hline & CAPINVEST & GDP & GVTSPE & INFLAT & TOT \\
\hline CAPINVEST & 1.000000 & 0.586886 & 0.325385 & -0.221040 & 0.339253 \\
GDP & 0.586886 & 1.000000 & 0.299542 & 0.291043 & 0.498662 \\
GVTSPE & 0.325385 & 0.299542 & 1.000000 & 0.1717625 & 0.551832 \\
INFLAT & -0.221040 & -0.291043 & 0.1717625 & 1.000000 & -0.211606 \\
TOT & 0.339253 & 0.498662 & 0.551832 & -0.211606 & 1.000000 \\
UNEMP & 0.477344 & 0.281781 & -0.225624 & -0.263218 & -0.044738 \\
\hline
\end{tabular}

In this study there is weak multi-collinearity among variables as reflected by the coefficient of less than 0.8 . The correlation tests show a negative relationship between the two macroeconomic variables under study namely GDP and inflation.
Stationarity Tests

The stationarity or unit root test of the data used in this study were conducted using Augmented Dickey Fuller Test and the results are shown below.

Table 3. Augmented Dickey Fuller (ADF) Test Results after differencing.

\begin{tabular}{|c|c|c|c|c|c|}
\hline Variable & t-ADF Statistic & Critical1\% & Critical5\% & Critical10\% & Conclusion \\
\hline CAPINVEST & -4.324251 & $-3.711457 *$ & -3.981038 & $-2.629906 * *$ & $\mathrm{I}(2)$ \\
\hline GDP & -3.204882 & $-3.699871 *$ & -2.976263 & $-2.627420 * *$ & $\mathrm{I}(0)$ \\
\hline GVTSPE & -4.945784 & $-3.711457 *$ & -2.981038 & $-2.629906^{* *}$ & $\mathrm{I}(2)$ \\
\hline INFLAT & -7.196901 & -3.699871 & -2.976263 & $-2.627420 * *$ & $\mathrm{I}(0)$ \\
\hline TOT & -7.034203 & -3.724070 & -2.986225 & $-2.632604 * *$ & $\mathrm{I}(2)$ \\
\hline UNEMP & -3.204241 & $-3.669871^{*}$ & -2.976263 & $-2.627420 * *$ & $\mathrm{I}(0)$ \\
\hline
\end{tabular}

$*, * *$ indicate significance at $1 \%$ and $10 \%$ respectively

The results from the ADF test became stationary after differencing. GDP, inflation and unemploymentbecame stationary at levels.Before conducting cointegration test, the statistical properties of the model were assessed. Diagnostic tests were carried out to test for serial-correlation, heteroscedasticity, normality and specification. The results are presented in Table 4 below: 
Table 4. Diagnostic Tests.

\begin{tabular}{lll}
\hline & F. Statistic & Probability \\
\hline Specification Error: Ramsey Reset Test & 3.114643 & 0.024190 \\
Serial Correlation: Breusch-Godfrey Serial Correlation LM Test & 0.278333 & 0.955163 \\
AR Conditional Heteroscedasticity (ARCH): Breusch -Pagan- Godfrey & 0.200163 & 0.958978 \\
Normality: Jacque-Bera & 0.163005 & 0.921730 \\
\hline
\end{tabular}

As shown in table 4 above, the diagnostic tests carried out show that the model is reasonably well specified and that the residuals are homoscedastic and serially uncorrelated. The next stage involves testing for the existence of cointegration relationship among the variables.

Cointegration Test

Table 5. Johansen Technique Results (Trace).

\begin{tabular}{llll}
\hline Hypothesize No. of CEs & Eigenvalue & Trace Statistic & 5\% Critical Value \\
\hline None* & 0.748448 & 100.5170 & 95.75366 \\
At most 1 & 0.646170 & 64.63424 & 69.81889 \\
At most 2 & 0.551474 & 37.62182 & 47.85613 \\
At most 3 & 0.297990 & 16.77532 & 29.79707 \\
At most 4 & 0.226643 & 7.576310 & 15.49471 \\
At most 5 & 0.033798 & 0.893929 & 3.841466 \\
\hline
\end{tabular}

*Denotes rejection of the hypothesis at the $5 \%$ significance level.

Using the Johansen cointegration, there is evidence of cointegration between GDP and its explanatory variables. With these results, the study proceeded to estimate the OLS equation. The results are shown in table 6 below.

Ordinary Least Squares Estimation

Table 6. Ordinary Least Squares (OLS) Results.

Dependent Variable: GDP

\begin{tabular}{lllll}
\hline Variable & Co-Efficient & Std. Error & t-Statistic & Prob \\
\hline Inflat & -0.012502 & 0.039778 & -0.314289 & 0.0728 \\
CapInvest & 0.543996 & 0.274881 & 1.979022 & 0.0611 \\
GvtExp & -0.107687 & 0.306219 & -0.535291 & 0.7286 \\
ToT & 0.595069 & 0.316538 & -1.624236 & 0.0741 \\
Unemp & -0.839845 & 2.907191 & 1.381263 & 0.7755 \\
C & -67.72614 & 33.70253 & 0.824444 & 0.0575 \\
\hline
\end{tabular}

R-Squared $=0.470871$

Adjusted R-Squared $=0.319691$

F-Statistic $=3.114643$

Durbin Watson Statistic (DW) $=1.514931$

Table 6 shows the estimated results exhibiting the coefficient values of the explanatory variables as well as indicating through the probability value whether each respective variable is significant. According to the estimated model above, the relationship between economic growth (GDP) and inflation (INFLAT) exhibits a negative coefficient of 0.012502 , against a P-value of 0.0728 . This suggests that a unit increase in inflation would result in 0.01 decrease in economic growth, hence a statistically insignificant $\mathrm{P}$-value.The value of the adjusted $\mathrm{R}$-squared is $47 \%$, suggesting that $47 \%$ variation in gross domestic product is explained by the variation in the independent variables. The DW of 1.51 means that there is no serial correlation in the variables.

\section{Conclusion}

This study found out that an increase in the general price level (inflation) has an insignificant impact on economic growth in Zimbabwe. These results have important policy implications for both domestic policy makers and development partners, implying that controlling inflation is a necessary but not a pre-condition for promoting economic growth in Zimbabwe.

\section{Policy Recommendations}

Thus, as a standing policy, the Zimbabwean government should focus on maintaining inflation at a low rate (single digit). In this regard the study concluded that all factors which cause an increase in the general price levels such as energy (petrol, diesel, gasoline, paraffin), exchange rates volatility, increase in money supply, poor agricultural production and so forth should be kept on check, with the appropriate policies so as to foster economic growth.

Since the double-digit inflation rate in Zimbabwe was mainly due to energy crisis and poor agricultural produce, the government should use other sources of power such as gas as an alternative to hydro-electricity.Constant availability of power is of great important for production since the more the country produces the less the prices of goods and services hence higher economic growth. Similarly, agricultural produce may be increased by improving infrastructure, provision of labour force, training to farmers as well as strategies like loan provision schemes with affordable interest rates and establishment of permanent markets for their products should be undertaken. The elasticity coefficient of GDP to inflation rate is rather inelastic in Zimbabwe. To policy makers, this could imply that even if there are other factors which influence economic growth such as positive 
terms of trade, capital investment and capital expenditure, inflation remain a significant macro-economic variable requires constant check. Thus, to attain and sustain high economic growth (GDP) policy makers in Zimbabwe should strive to keep inflation rate at a possible minimum rate.

\section{References}

[1] Ahmed, S. (2010). 'An Empirical Study on Inflation and Economic Growth in Bangladesh'. OIDA International Journal of Sustainable Development. Vol. 2, No. 3, pp. 41-48.

[2] Chimobi, O. (2010). Inflation and Economic Growth in Nigeria. Journal of Sustainable Development, Vol. 3, No. 2, pp. 44-51.

[3] IMF. (2009). Statement at the Conclusion of an IMF Staff Mission to Zimbabwe. Press Release 09/249, http://www.imf.org/external/np/sec/pr/2009/pr09249.

[4] Makuyana G, Munongo S, and Zivanomoyo, J (2011).Does the Zimbabwean exchange rate follow a random walk: January 2000 - December 2008?Journal of Economics and International Finance Vol. 3(2), pp.121-124, February 2011.

[5] Economic Outlook (2018): Zimbabwe Economy Unemployment and Inflation Statistics.

[6] Fischer, S. (1993). The Role of Macroeconomic Factors in Growth. Journal of Monetary Economics, Vol. 47, No. 5, pp. 485-512.

[7] Barro, R. (1995). 'Inflation and economic growth': NBER Working Paper 53(26) 166-176.

[8] Bruno, M and Easterly, W (1996). Inflation and Growth, in search of a stable relationship: A Review Paper. Federal Reserve Bank.

[9] Ghosh, A. and Phillips, S. (1998). Warning: Inflation May Be Harmful to Your Growth, IMF Staff Papers, Vol. 45, No. 4, pp. 672-710.
[10] Quartey, P. (2010). Price Stability and the Growth Maximizing rate of inflation for Ghana, Business and Economic Journal, Vol. 1, No. 1, pp. 180-194.

[11] Hasanov, F. (2010). Relationship between Inflation and Economic Growth in Azerbaijani Economy': Is there any Threshold Effect? Asian Journal of Business and Management Sciences, Vol. 1, No. 1, pp. 6-7.

[12] Umaru, A. and Zubairu, J. (2012). The Effect of Inflation on the Growth and Development of the Nigerian Economy: An Empirical Analysis, International Journal of Business and Social Science, Vol. 3, No. 10, pp. 187-188.

[13] Frimpong, M. and Oteng-Abayie, F. (2010). When is Inflation harmful? Estimating the Threshold Effect for Ghana, American Journal of Economics and Business Administration, Vol. 2, No. 3, pp. 232-239.

[14] Bick, A. Kremer, S. and Nautz, D. (2009). 'Inflation and Growth: New Evidence from a Dynamic Panel Threshold Analysis'. SFB 649 Discussion Paper 036. pp. 33-47.

[15] Khan, M. and Senhadji, S. (2001). Threshold Effects in the Relationship between Inflation and Growth, IMF Staff Papers, Vol. 48, No. 1, pp. 1-21.

[16] Nell, K. (2000). Is Low Inflation a Precondition for Faster Growth, The Case of South Africa, Department of Economics, University of Kent, United Kingdom.

[17] Sergii, P. (2009). Inflation and Economic Growth: The NonLinear relationship. Evidence from CIS Countries, Kyiv School of Economics, Ukraine.

[18] Espinoza, R., Leon, H. and Prasad, A. (2010). Estimating the Inflation-Growth Nexus-A Smooth Transition Model, IMF Working Paper. Vol. 10, No. 76, pp. 2-9.

[19] Mehari, M. and Wondafrash, A. (2008). The Impact of Money Supply on Inflation in Ethiopia.

[20] Mwase, N. (2006). An Empirical Investigation of the Exchange Rate Pass-Through to Inflation in Tanzania, IMF Working Paper /06/150, 4-7. 